\title{
THE TEMPORAL SCOUR PROGRESS DOWNSTREAM OF LOW-HEAD STILLING BASINS UNDER UNSTEADY FLOW
}

\author{
GIUSEPPE OLIVETO \\ School of Engineering, University of Basilicata, Italy
}

\begin{abstract}
This paper deals with the temporal evolution of local scour downstream of low-head stilling basins. In comparison to previous companion papers the most real conditions of unsteady approach flow are considered here. In this aim, experiments were carried out in a $1 \mathrm{~m}$ wide and $20 \mathrm{~m}$ long rectangular channel. Free overfall jets plunging into a horizontal apron were caused by an ogee-crested spillway. A nearly-uniform sediment with median grain size $d_{50}=9 \mathrm{~mm}$ was used as mobile bed. The temporal effect of six different hydrographs on local scour depth was investigated under clear-water scour condition. Based on the data collected and the previous results for steady flow conditions a predictive model is proposed to simulate the temporal progress of the scour depth along the channel axis as function of tailwater densimetric Froude number, relative submergence, and dimensionless time.

Keywords: local scour, sediment transport, stilling basin, unsteady flow.
\end{abstract}

\section{INTRODUCTION}

A fundamental aspect of river-drop structures design is the prediction of local scour which can occur downstream of them. The flow over these structures has a significant potential for scour even for comparatively low heads. Hence stilling basins are commonly built to keep energy flows from scouring the streambed. However, the flow turbulence intensity within them is often high and local bed scour can develop. Though numerous studies on local scour below low-head spillways have been made, the results are still not satisfactory especially in regard to the spatial and temporal evolution of the local bed morphology. Literature reviews are given by Breusers and Raudkivi [1], Hager [2], Hoffmans and Verheij [3], and Sarkar and Dey [4].

Breusers [5] carried out a wide-ranging work using various bed materials of different densities and geometric configurations. A formula for the temporal scour evolution was proposed. Kuti and Yen [6] considered cohesive sediment beds analysing the influence of clay minerals mixed with cohesion-less soils. Numerous tests were performed by Farhoudi and Smith [7], [8] considering six different materials. Results were in agreement with those of Breusers [5]. Gisonni and Rasulo [9] suggested an approach to estimate the scour depth at the equilibrium stage as function of the turbulence intensity coefficient and the reduced critical velocity for the initiation of sediment transport. Dargahi [10] made an experimental study to examine the similarity of scour profiles and the scour geometry. No experimental evidence was found in support of the similarity. Power-law type equations were introduced to predict the scour geometry. Adduce and Sciortino [11] presented both numerical and experimental investigations on local scour downstream of a sill followed by a rigid apron. Adduce and La Rocca [12] investigated the different scouring processes due to different jets developing downstream of a trapezoidal drop followed by a rigid apron. Farhoudi et al. [13] investigated the performance of a neuro-fuzzy model in estimating the properties of scour hole downstream of a U.S.B.R. Type I stilling basin. Results showed a significant agreement between estimated and experimental data. Finally, Pagliara and Palermo [14] assessed the effect of both the width and length of stilling basins on scour features and flow pattern 
downstream of a block ramp. More recently, Farhoudi and Shayan [15] have studied local scour downstream of adverse stilling basins. The results showed that the scour profiles follow shape similarity. Fakhari and Kabiri-Samani [16] have experimentally investigated local scour processes in the transition from super- to sub-critical flow without a hydraulic jump. Palermo and Pagliara [17] have analysed the evolution of the scour morphology under unsteady flow conditions considering three control-structures typologies: stepped gabion weirs, straight rock sills, and curved rock sills. The results showed the scour phenomenon deeply depended on inflow conditions.

However, the above studies mainly consider the maximum scour depth at a quasiequilibrium state and steady flow approach conditions while available results on the temporal and spatial local bed morphology changes as well as on unsteady flow conditions are very limited. Then the present study, that follows previous contributions by Oliveto and Comuniello, [18], Oliveto et al. [19], and Oliveto [20], aims to consider and analyse the most real condition of unsteady approach flow conditions. The results could be useful for practical applications.

\section{EXPERIMENTS}

Experiments were carried out in a $1 \mathrm{~m}$ wide and $20 \mathrm{~m}$ long rectangular straight channel at the University of Basilicata, Italy. An ogee-crested spillway with stilling basin was placed in the channel $6 \mathrm{~m}$ from the inlet. The weir height above the downstream undisturbed bed level, $w$, was $0.20 \mathrm{~m}$. The stilling basin consisted of a plain apron with $l=1.65 \mathrm{~m}$.

A nearly-uniform sediment with density $\rho_{s}=2650 \mathrm{~kg} / \mathrm{m}^{3}$, median grain size $d_{50}=9 \mathrm{~mm}$ and sediment gradation $\sigma=\left(d_{84} / d_{16}\right)^{0.5}=1.5$ was used as mobile bed. Gravel was used to better explore sediment grain size effects and also to simulate the presence of something like a riprap bed protection. The undisturbed bed surface was horizontal and flushed with the stilling basin end.

Due to the intrinsic difficulties in reproducing real-shaped hydrographs, stepped hydrographs were generated instead. Changes in discharge between steps were made gradually to minimize flow acceleration or deceleration. Each step in the hydrograph was run for at least 0.5 up to 2 hours to observe substantial changes in bed morphology and to collect very replicable data. Moreover, all the experiments were performed keeping constant over the time the height of the rectangular sharp-crested weir located at the downstream end of the channel to control the tailwater depths. This height was set to avoid the overlapping of local and general scour phenomena even for peak discharges. In general, the hydraulic jump developed over the apron or slightly downstream. In total six runs were performed in which the peak discharge was either around 104 1/s or 123 l/s. However, these discharges were attained for different time steps $\Delta t$ in order to also analyse the effect of $\Delta t$ on the scour depth temporal progress.

The water discharge was measured with an orifice plate with accuracy of $\pm 3 \%$. The water surface was measured with a conventional point gauge with accuracy to the nearest millimetre and the sediment surface with a shoe gauge. Flow depths and bed levels were measured along the channel axis at around the middle of each temporal step. Axial bed readings were taken with water continuing to flow. However, a detailed survey on the bed morphology features was done at the end of each experiment after stopping the flow.

Fig. 1 shows the flow conditions for the Run UF_1 with a peak discharge $Q_{\max }=103.6 \mathrm{l} / \mathrm{s}$ and corresponding tailwater depth $h_{t w, \max }=0.20 \mathrm{~m}$. More in particular, a five-steps hydrograph was generated with discharges $Q$ equal to $68.9,89.2,103.6,90.2$, and $69.8 \mathrm{1} / \mathrm{s}$ and corresponding tailwater depths, $h_{t w}$, equal to $0.165,0.186,0.200,0.187$, and $0.166 \mathrm{~m}$. The hydraulic jump was not stable under these conditions and the observed horizontal distances, 
$l_{t}$, of toe of the jump from the apron edge at the five hydrograph steps were $0.572,0.522$, $0.539,0.842$, and $1.280 \mathrm{~m}$, respectively. Photographs XIII and XIV refer to the second step, photographs XV and XVI to the third step, photographs XVII and XVIII to the fourth step, and photographs XIX and XX to the fifth step.

Fig. 2 shows stepped hydrographs corresponding to each run. Four hydrographs were nearly symmetrical in shape while two were asymmetrical patterned with the rising limb duration longer than that of the falling limb, despite the natural evidence to the contrary. However, this paper mainly aims to assess the suitability of the proposed approach that will be described in Section 3 to predict unsteady flow conditions independently of the hydrograph shape.

\section{ANALYSIS OF DATA}

Based on 22 runs performed under approach steady flow conditions, Oliveto [20] suggested the following equation to predict the temporal progress of the maximum scour depth downstream of a low-head spillway with a horizontal apron

$$
Z=\frac{z}{h_{t w}}=0.16 \mathrm{~F}_{d}^{1.68}\left(\frac{l_{t}}{h_{t w}}\right)^{-0.49}\left(\frac{h_{t w}}{d_{50}}\right)^{-0.22} \sigma^{-1.41} T^{0.19}
$$

where $z=$ maximum scour depth at a given time $t, \mathrm{~F}_{d}=V /\left(g^{\prime} d_{50}\right)^{1 / 2}$ densimetric Froude number at the tailwater section with $V$ cross sectional flow velocity, $g^{\prime}=g\left(\rho_{s}-\rho\right) / \rho$ modified gravitational acceleration, $\rho$ mass density of water, $\rho_{s}$ mass density of bed sediment, and
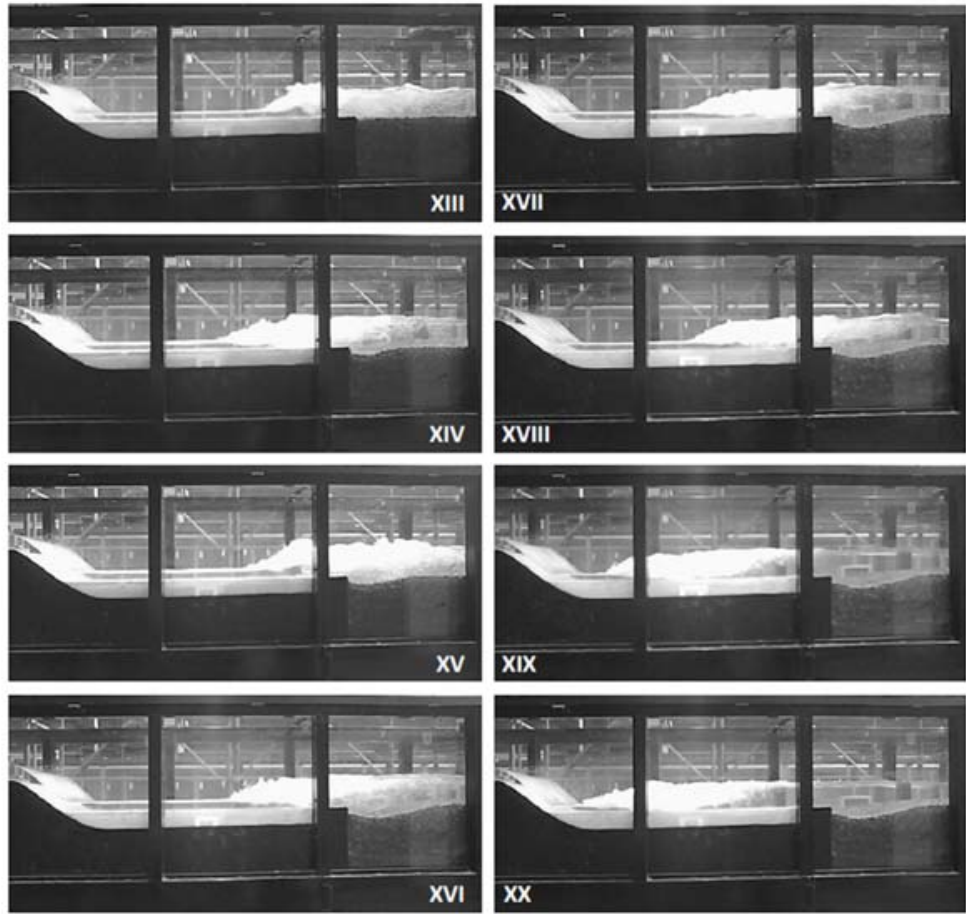

Figure 1: Free surface and bed morphology observed during the Run UF_1 at states from XIII to XX. Flow is from left to right. 


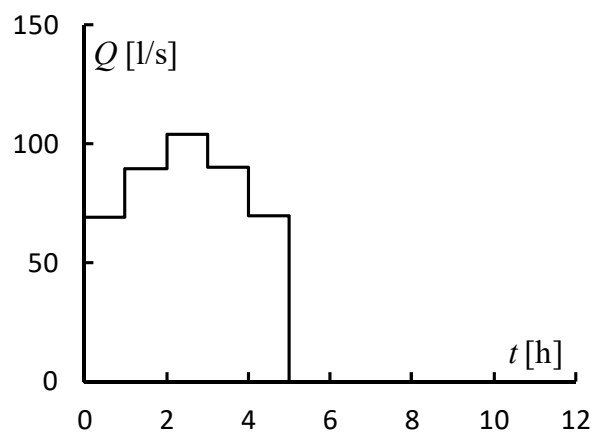

(a)

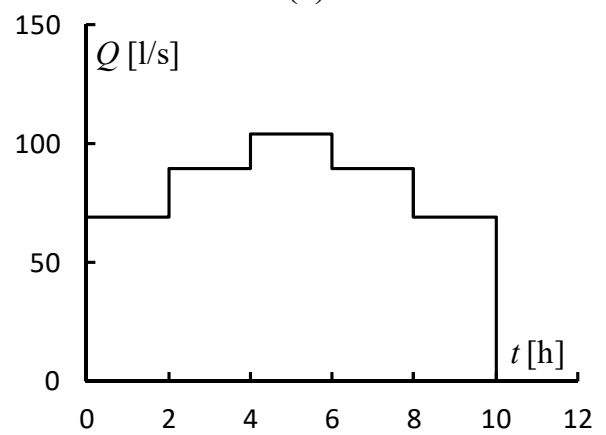

(c)

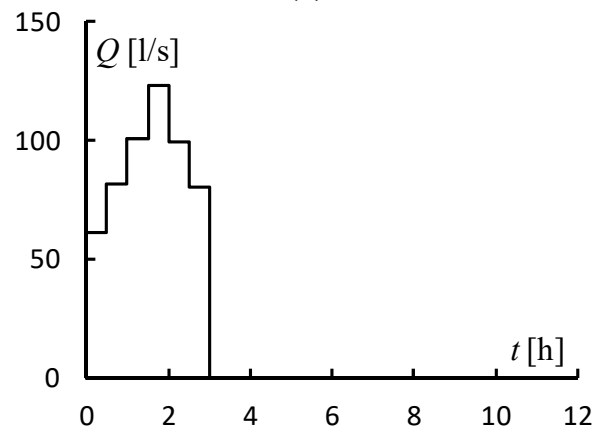

(e)

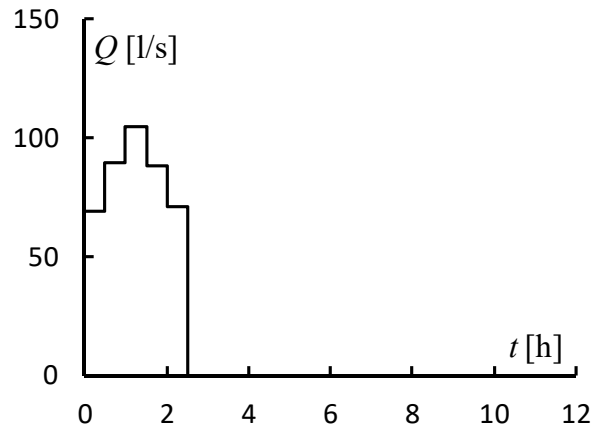

(b)

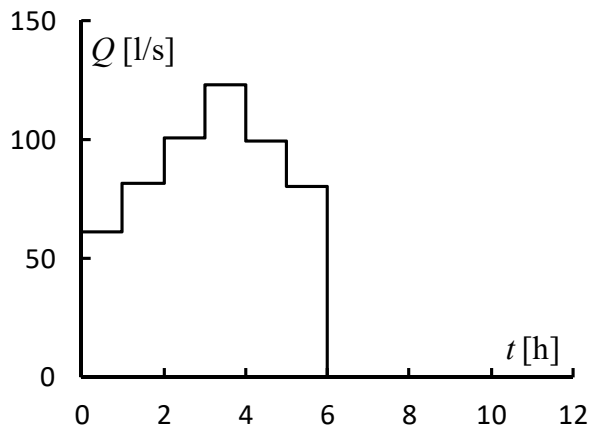

(d)

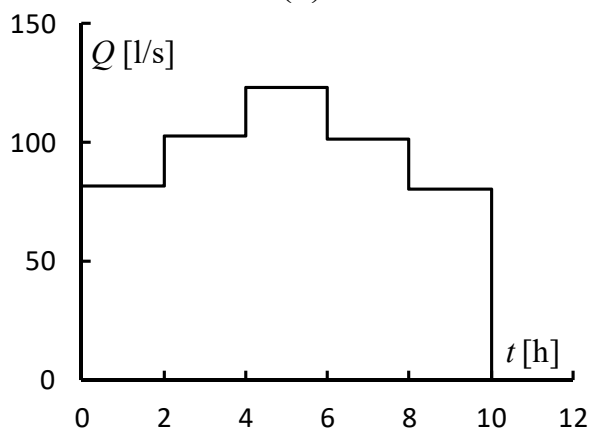

(f)

Figure 2: Six types of stepped hydrographs simulated in this experimental study. (a) Run UF_1 with Qmax 103.6 1/s and htw, $\max 0.200 \mathrm{~m}$; (b) Run UF_2 with Qmax 104.7 1/s and htw, max 0.202 m; (c) Run UF 3 with Qmax $103.61 / \mathrm{s}$ and htw,max $0.200 \mathrm{~m}$; (d) Run UF 4 with Qmax $123.2 \mathrm{l} / \mathrm{s}$ and htw,max $0.215 \mathrm{~m}$; (e) Run UF_5 with Qmax 123.2 1/s and htw, max $0.215 \mathrm{~m}$; and (f) Run UF_6 with Qmax $123.2 \mathrm{l} / \mathrm{s}$ and $\mathrm{htw}, \max 0.215 \mathrm{~m}$.

$g Z=\frac{z}{h_{t w}}=0.16 \mathrm{~F}_{d}^{1.68}\left(\frac{l_{t}}{h_{t w}}\right)^{-0.49}\left(\frac{h_{t w}}{d_{50}}\right)^{-0.22} \sigma^{-1.41} T^{0.19}$ gravitational acceleration, $l_{t}=$ horizontal distance of toe of the jump from the apron edge at a given time $t$, and $T=$ dimensionless time $=\left(g^{\prime} d_{50}\right)^{1 / 2} t / h_{t w}$. Main ranges of applicability of eqn (1) are 
$2.4 \cdot 10^{3} \leq T \leq 1.4 \cdot 10^{6}, 1.30 \leq \mathrm{F}_{d} \leq 2.87$, and $1.2 \leq l_{t} / h_{t w} \leq 11.0$. However, further experiments varying $\sigma$ are needed to identify more reliable values of its exponent.

For unsteady flows, eqn (1) could be applied by using an analogous approach as in Oliveto and Hager [21] in case of bridge piers. The computation of scour depth can proceed as follows:

- $\quad$ At time $t=0$ one has $Z=0$, whereas at time $t_{1}=0+\Delta t, T_{1}=\left(g^{\prime} d_{50}\right)^{1 / 2} t_{1} /\left(h_{t w}\right)_{0,1}$ where $\left(h_{t w}\right)_{0,1}$ is the tailwater depth at the first step of the hydrograph. Dimensionless scour depth at $T_{1}$ is $Z_{1}$ computed according to eqn (1). Then, $z_{1}$ at the time $t_{1}$ is $z_{1}=Z_{1} \cdot\left(h_{t w}\right)_{0,1}$;

- In the interval $\left(t_{1}, t_{2}\right)$ at the time $t_{1}$ the dimensionless scour depth is $Z_{1}=z_{1} /\left(h_{t w}\right)_{1,2}$ where $\left(h_{t w}\right)_{1,2}$ is the tailwater depth at the second step. The corresponding time $T_{1}$ is $\left[Z_{1} /\left[0.16\left(F_{d}\right)_{1,2}{ }^{1.68}\left[\left(l_{t}\right)_{1,2} /\left(h_{t w}\right)_{1,2}\right]^{-0.49}\left[\left(h_{t w}\right)_{1,2} / d_{50}\right]^{-0.22} \sigma^{-1.41}\right]^{1 / 0.19}\right.$ from eqn (1) and dimensional time $t_{1}{ }_{1}$ is $T_{1} \cdot\left(h_{t w}\right)_{1,2} /\left(g^{\prime} d_{50}\right)^{1 / 2}$. Then it results $T_{2}=\left(g^{\prime} d_{50}\right)^{1 / 2} t_{2}{ }_{2} /\left(h_{t w}\right)_{1,2}$ with $t^{\prime}{ }_{2}=t^{\prime}{ }_{1}+\Delta t$ and $Z_{2}=0.16\left(\mathrm{~F}_{d}\right)_{1,2}{ }^{1.68}\left[\left(l_{t}\right)_{1,2} /\left(h_{t w}\right)_{1,2}\right]^{-0.49}\left[\left(h_{t w}\right)_{1,2} / d_{50}\right]^{-0.22} \sigma^{-1.41} T_{2}{ }^{0.19}$. Finally, $z_{2}=Z_{2} \cdot\left(h_{t w}\right)_{1,2}$;

- The above procedure is repeated until the last step of the hydrograph.

Fig. 3 shows the comparison between observed and computed maximum scour depths along the channel axis according to the proposed approach. In general, the agreement between experimental observations with computations can be considered acceptable. Deviations, $\left(z_{\mathrm{ob}}-z_{\mathrm{com}}\right) / z_{\mathrm{ob}}$, between the final observed and computed values were found equal to $18 \%$ on average and ranging between $-0.03 \%$ up to $38 \%$. The largest discrepancies were found for the smallest step $\Delta t$ (i.e. $\Delta t=0.5 \mathrm{~h}$ ) probably because flow acceleration was not negligible in that runs. Conversely, a more suitable agreement was found in case of unsteady gradually flow (i.e. $\Delta t=1$ to $2 \mathrm{~h}$ ). According to the proposed procedure the final scour depth should decrease as $\Delta t$ decreases for the same peak discharge and hydrograph shape. However, this effect was only slightly observed. In any case the observed final scour depth was always found less (with considerable deviations, $\left(z_{\mathrm{eq}}-z_{\mathrm{ob}}\right) / z_{\mathrm{eq}}$, around $47 \%$ on average) than that computed from eqn (1) considering a quasi-equilibrium state $\left(T\right.$ around $\left.10^{6}\right)$ and steady flow conditions with discharge equal to the peak discharge.

\section{CONCLUSIONS}

Laboratory experiments on local scour downstream of a horizontal apron under unsteady approach flow were carried out at the Hydraulic Engineering Laboratory, University of Basilicata, Italy. Due to the difficulties in reproducing real-shaped hydrographs, stepped hydrographs were generated instead. Each step in the hydrograph was run for at least 0.5 up to 2 hours to observe substantial changes in bed morphology. In total six runs were performed in which the peak discharge was either around $104 \mathrm{l} / \mathrm{s}$ or $123 \mathrm{l} / \mathrm{s}$. On average at the tailwater section $1.09 \leq \mathrm{F}_{d} \leq 1.36,2.69 \leq l_{t} / h_{t w} \leq 8.39$, and $18.37 \leq h_{t w} / d_{50} \leq 22.30$ for runs with peak discharge around $104 \mathrm{l} / \mathrm{s}$ and $1.10 \leq \mathrm{F}_{d} \leq 1.50,1.69 \leq l_{t} / h_{t w} \leq 6.65$, and $17.78 \leq h_{t w} / d_{50} \leq 23.89$ for runs with peak discharge around $123 \mathrm{l} / \mathrm{s}$. The main results can be summarized as follows:

- Overall the proposed approach provides satisfactory predictions in terms of temporal trend and final value of the maximum scour depth at the channel axis;

- Some discrepancies were found in case of stepped hydrographs with the smallest time-step considered here (i.e. $\Delta t=0.5 \mathrm{~h}$ ). This could be due to flow acceleration that the proposed approach does not consider; 
- Conversely, observed data are well predicted in case of unsteady gradually varied flow (i.e. $\Delta t=2 \mathrm{~h}$ );

- Finally, the proposed approach implies the estimation of $l_{t}$ (i.e. horizontal distance of toe of the jump from the apron edge) that is function of both hydraulic conditions and bed morphology. On this purpose, the momentum equation can be applied by considering only the hydraulic conditions as a first approximation.

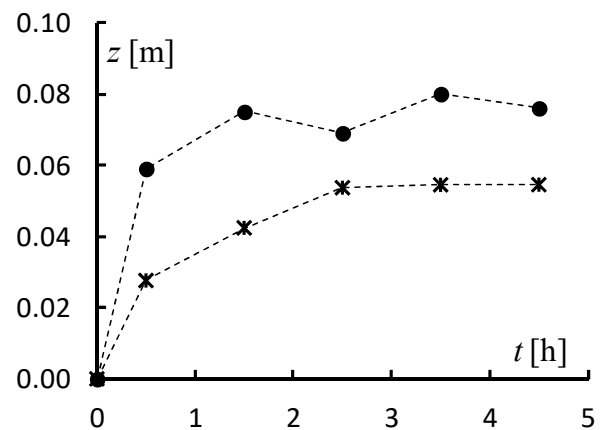

(a)

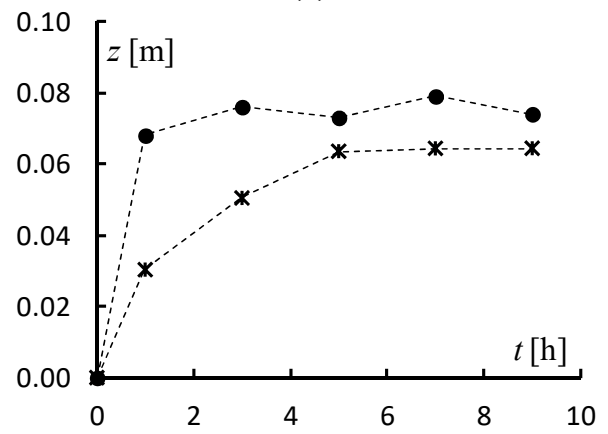

(c)

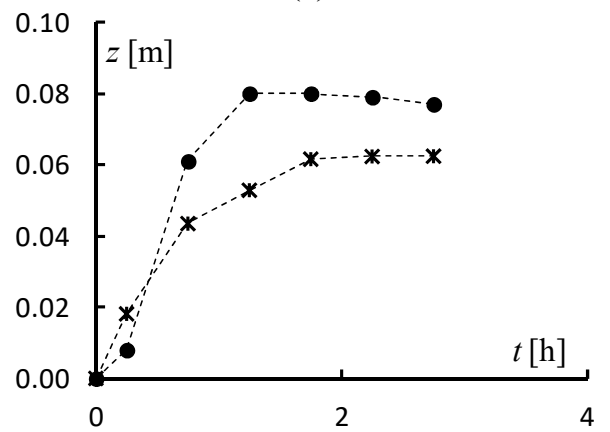

(e)

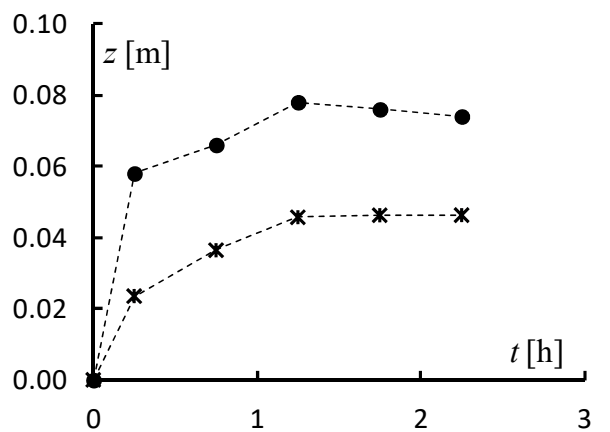

(b)

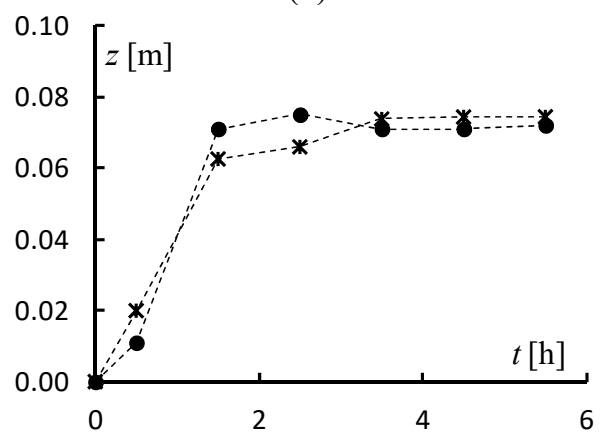

(d)

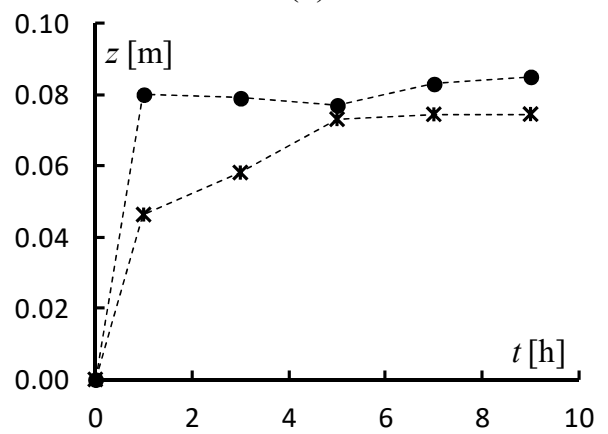

(f)

Figure 3: Comparison between observed (--•--) and computed (--*--) maximum scour depths along the channel axis. (a) Run UF_1; (b) Run UF_2; (c) Run UF_3; (d) Run UF_4; (e) Run UF_5; and (f) Run UF_6. 


\section{REFERENCES}

[1] Breusers, H.N.C. \& Raudkivi, A.J., Scour manual, A.A. Balkema: Rotterdam, pp. 123-140, 1991.

[2] Hager, W.H., Energy dissipaters and hydraulic jump, Kluwer Academic Publishers: Dordrecht, pp. 191-205, 1992.

[3] Hoffmans, G.J.C.M. \& Verheij, H.J., Scour manual, A.A. Balkema: Rotterdam, pp. 68-76, 1997.

[4] Sarkar, A. \& Dey, S., Review on local scour due to jets. International Journal of Sediment Research, 19(3), pp. 210-238, 2004.

[5] Breusers, H.N.C., Time scale of two-dimensional local scour. Proceedings of the 12th IAHR Congress, 3, pp. 275-282, 1967.

[6] Kuti, E.O. \& Yen, C.L., Scour of cohesive soils. Journal of Hydraulic Research, 14(3), pp. 195-206, 1976.

[7] Farhoudi, J. \& Smith, K.V.H., Time scale for scour downstream of hydraulic jump. Journal of Hydraulic Engineering, 108(10), pp. 1147-1162, 1982.

[8] Farhoudi, J. \& Smith, K.V.H., Local scour profiles downstream of hydraulic jump. Journal of Hydraulic Research, 23(4), pp. 343-358, 1985.

[9] Gisonni, C. \& Rasulo, G., Local scouring downstream of positive step stilling basins. Proceedings of the 27th IAHR Congress, D, pp. 423-428, 1997.

[10] Dargahi, J., Scour development downstream of a spillway. Journal of Hydraulic Research, 41(4), pp. 417-426, 2003.

[11] Adduce, C. \& Sciortino, G., Scour due to a horizontal turbulent jet: numerical and experimental investigation. Journal of Hydraulic Research, 44(5), pp. 663-673, 2006.

[12] Adduce, C. \& La Rocca, M., Local scouring due to turbulent water jets downstream of a trapezoidal drop: laboratory experiments and stability analysis. Water Resources Research, 42(2), W02405, 2006.

[13] Farhoudi, J., Hosseini, S.M. \& Sedghi-Asl, M., Application of neuro-fuzzy model to estimate the characteristics of local scour downstream of stilling basins. Journal of Hydroinformatics, 12(2), pp. 201-211, 2010.

[14] Pagliara, S. \& Palermo, M., Effect of stilling basin geometry on clear water scour morphology downstream of a block ramp. Journal of Irrigation and Drainage Engineering, 137(9), pp. 593-601, 2011.

[15] Farhoudi, J. \& Shayan, H.K., Investigation on local scour downstream of adverse stilling basins. Ain Shams Engineering Journal, 5(2), pp. 361-375, 2014.

[16] Fakhari, Z. \& Kabiri-Samani, A., Scour in the transition from super-to subcritical flow without a hydraulic jump. Journal of Hydraulic Research, 2017, Online. http://dx.doi.org/10.1080/00221686.2016.1275052.

[17] Palermo, M. \& Pagliara, S., Effect of unsteady flow conditions on scour features at low-head hydraulic structures. Journal of Hydro-environment Research, 2017, Online. https://doi.org/10.1016/j.jher.2017.04.001.

[18] Oliveto, G. \& Comuniello, V., Local scour downstream of positive-step stilling basins. Journal of Hydraulic Engineering, 135(10), pp. 846-851, 2009.

[19] Oliveto, G., Comuniello, V. \& Bulbule, T. Time-dependent local scour downstream of positive-step stilling basins. Journal of Hydraulic Research, 49(1), pp. 105-112, 2011.

[20] Oliveto, G., Local scouring downstream of a spillway with an apron. Water Management ICE, 166(5), pp. 254-261, 2013.

[21] Oliveto, G. \& Hager, W.H., Further results to time-dependent local scour at bridge elements. Journal of Hydraulic Engineering, 131(2), pp. 97-105, 2005. 